\title{
GLOBAL WATER PARTNERSHIP E AS IDEIAS-CHAVE EM SUA NOVA ESTRATÉGIA GLOBAL 2020-2025
}

\section{GLOBAL WATER PARTNERSHIP AND THE KEY IN ITS NEW GLOBAL STRATEGY 2020-2025}

\section{Carlos Hiroo Saito}

Universidade de Brasília, Brasília-DF, Brasil Global Water Partnership, GWP-Brasil, Brasília, DF, Brasil. E-mail: carlos.h.saito@hotmail.com Como citar: Saito, C. H. Global water partnership e as ideias-chave em sua nova estratégia global 2020-2025. Revista de Gestão de Água da
América Latina, v. 16, e13, 2019. https://dx.doi.org/10.21168/rega.v16e13.

RESUMO: 0 artigo apresenta a nova Estratégia da Global Water Partnership (GWP) para o período 2020-2025, fazendo não apenas uma síntese do referido documento e suas formas previstas de implementação, mas também uma análise crítica de pressupostos e ideias-chave nele contidas. 0 texto também traz uma análise do contexto em que essa estratégia global foi produzida, que justificam o perfil apresentado pelo documento. 0 texto ainda estabelece relações entre a referida estratégia e a nova Década Internacional para Ação "Água para o Desenvolvimento Sustentável" (2018-2028), e analisa seu rebatimento na América do Sul.

PALAVRAS-CHAVE: segurança hídrica, gestão integrada de recursos hídricos, crise hídrica, GWP, Década Internacional para Ação "Água para o Desenvolvimento Sustentável”

ABSTRACT: The article presents the new Global Water Partnership (GWP) Strategy for the period 2020-2025, not only summarizing the document and its intended implementation, but also offering a critical analysis of the assumptions and key ideas contained therein. It also brings an analysis of the context in which this Global Strategy is conceived, which justify the profile presented by the document. Additionally, the text establishes links between this strategy and the new International Decade for Action "Water for Sustainable Development" (2018-2028), and analyzes its rebound in South America.

KEYWORDS: water security, integrated water resources management, water crisis, GWP, International Decade for Action "Water for Sustainable Development"

\section{INTRODUÇÃO}

Em 27 de agosto de 2019, em Estocolmo, a rede internacional Global Water Partnership-GWP lançou formalmente sua nova estratégia global para o período 2020-2025 (Figura 1) (Global Water Partnership, 2019). GWP é uma rede internacional criada em 1996 com a missão de promover a Gestão Integrada de Recursos Hídricos em escala global (http://www.gwp.org). A rede surge em decorrência de um chamamento do PNUD e do Banco Mundial à comunidade internacional para o desenvolvimento de uma Associação Mundial pela Água em 1995. Atualmente a GWP conta com mais de 3000 organizações afiliadas distribuídas por 179 países, tendo ainda conseguido organizar uma instância regional de secretariado em 13 regiões do globo, contando ainda com 68 organizações reconhecidas em nível nacional. Com sede em Estocolmo, Suécia, busca mobilizar e organizar as ações do conjunto da rede por meio de encontros periódicos e um plano estratégico revisto periodicamente. 


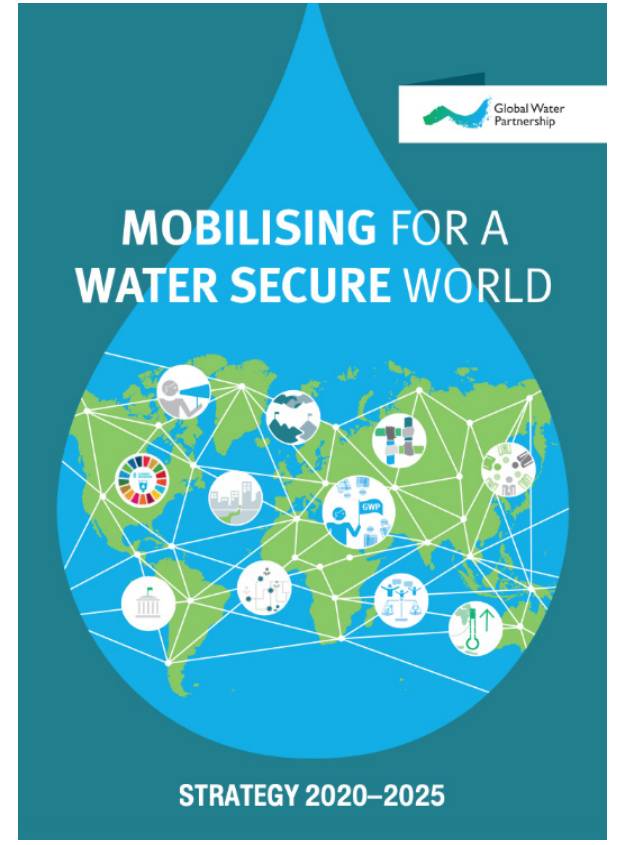

Figura 1. Documento da Estratégia GWP 2020-2025 (GWP, 2019).

Para melhor compreender essa nova estratégia 2020-2025 recém-aprovada, é preciso situá-la na linha do tempo, analisando-a conjuntamente com a estratégia anterior 2014-2019.

A estratégia 2014-2019 foi gestada num contexto bastante diferente da atual: não existia a Agenda 2030, com seus Objetivos de Desenvolvimento Sustentável. Finalizava-se a Década Internacional 2005-2015 para Ação "Água para a Vida" (Assembléia Geral/Resolução: A/RES/58/217), e o Fórum Mundial da Água mostra uma inflexão mais participativa e social de 2015 (Coréia do Sul) a 2018 (Brasil). Vivia-se também um certo otimismo a partir do processo de debates que culminou no Acordo de Paris (no âmbito da Convenção-Quadro das Nações Unidas sobre a Mudança do Clima) finalizado durante a COP21, e aprovado em 12 de dezembro de 2015. No saldo global, a temática da água se consolidava como uma das temáticas mais valorizadas no âmbito da ONU (Saito, 2017).

Mas globalmente uma nuvem sombria de crise econômica e política paira no ar. De acordo com Mervyn King, ex-presidente do Banco da Inglaterra, o mundo já está caminhando para uma nova crise econômica e financeira, conforme análise apresentada em Washington em encontro anual do Fundo Monetário Internacional (Elliot, 2019). Os Estados Unidos da América sinalizam para a saída o Acordo de Paris em junho de 2017. O Brasil, seguindo a linha do presidente americano, adota discurso semelhante a partir da posse do novo presidente em janeiro de 2019, e muito embora não operacionalize a saída do acordo, cancela a realização da COP25. Em ambos os países, a pauta ambiental perde prioridade e sucumbe aos interesses econômicos predatórios de recursos naturais.

À guinada na política ambiental desses países soma-se um cenário de crise econômica global, que embora não confessa ou explicitamente instalada, observa-se uma dificuldade na arrecadação de fundos por organizações ambientais. Na verdade, o que conduziu a esse cenário de escassez é mais do que crise financeira. É também política, com arrefecimento dos conflitos separatistas, seja na escala intra-nacional como na escala regional. Nesta última categoria se situam os países que aprovam a saída de blocos regionais ou globais (como o caso do Reino Unido com seu Brexit), ou movimentos de questionamento de articulações regionais como o Mercosul. O questionamento sobre o papel do Conselho de Direitos Humanos das Nações Unidas, e da própria Organização das Nações Unidas (ONU), de forma direta ou velada, pela suspensão de repasses de contribuição financeira a este organismo internacional a ponto de afetar seu funcionamento normal em 2019 completam este cenário.

\section{IDEIAS-CHAVE NA ESTRATÉGIA GWP 2020-2025: MOBILIZANDO PARA UM MUNDO COM SEGURANÇA HÍDRICA}

Obviamente duas ideias-chave que vem subjacente ao título da estratégia 2020-2025 são a segurança hídrica e a mobilização. 
A segurança hídrica tem sido um conceito abraçado pela GWP desde os anos 2000, e por ela apresentado com contornos definidos naquele ano, o que leva muitos a dizerem que seria esta a primeira formulação e atribuírem sua originalidade à Global Water Partnership (GWP), como o fazem Jonathan Lautze \& Herath Manthrithilake (2012), e Eelco van Beek \& Wouter Lincklaen Arriens (2014). No entanto, Saito (2018) apresentou uma cronologia do termo, com datação anterior, baseado em Cook \& Bakker (2012), informando o aparecimento do termo em 1999, com Witter \& Whiteford (1999). Na definição apresentada pela Global Water Partnership, segurança hídrica representa uma situação em que cada pessoa tem acesso a água segura suficiente a um custo acessível para levar uma vida limpa, saudável e produtiva, garantindo simultaneamente que o meio ambiente seja protegido e aprimorado (Global Water Partnership, 2000).

Atualmente, a formulação mais difundida é aquela apresentada pela ONU-Água segundo a qual segurança hídrica representa a capacidade de uma população para assegurar o acesso sustentável a quantidades adequadas de água de qualidade aceitável para sustentar os meios de subsistência, o bem-estar humano e o desenvolvimento socioeconômico; para garantir a proteção contra tanto a poluição quanto os desastres relacionados com a água; e para preservar os ecossistemas, num clima de paz e estabilidade política (Un-Water, 2013). A evolução do conceito, desde a primeira formulação passando por diversas transformações é comentada em Saito (2018). Independentemente da paternidade do conceito, é inegável que a GWP tem sido uma grande defensora e divulgadora do conceito de segurança hídrica já nesta versão última da ONU-Água, apresentando o conceito em diversos documentos técnicos como Background Papers e Perspective Papers presentes no IWRM GWP Toolbox, um repositório de documentos de apoio aos tomadores de decisão a respeito de gestão integrada de recursos hídricos (https://www.gwp.org/en/learn/iwrm-toolbox/About_IWRM_ToolBox/).

No Brasil, influenciada pela GWP, a Agência Nacional de Águas (ANA) — que é membro da GWP e ocupou posições importantes na rede tanto no Brasil como globalmente - , levou a cabo juntamente com o Ministério do Desenvolvimento Regional a elaboração do Plano Nacional de Segurança Hídrica (PNSH), concluído em 2019 (Agência Nacional de Águas, 2019), ainda que haja maior ênfase no aspecto infraestrutural do que na visão sistêmica, pela natureza do contexto em que foi gestada.

A outra ideia-chave de mobilização relaciona-se com o próprio papel histórico da GWP de colocar a segurança hídrica no centro do debate, trazendo os diversos atores sociais envolvidos para a responsabilidade por uma gestão integrada de recursos hídricos. Essa ideia-chave está de acordo com o segundo princípio da Declaração de Dublin que estabelece que a gestão de recursos hídricos deve se dar dentro de uma abordagem participativa, envolvendo usuários e tomadores de decisão em todos os níveis de planejamento, gestão e política (Solanes \& Gonzales-Villarreal, 1999; Global Water Partnership, 2000).

No entanto, cabe assinalar que esta ideia-chave de mobilização está intimamente articulada a outras duas ideias-chave presentes no documento: urgência e escolhas.

A ideia-chave urgência representa a noção de premência do tempo e foi citada inclusive pela CEO da GWP, Monika Weber-Fahr, durante o seu lançamento. Para ela, o crescimento econômico, o crescimento populacional e o desastre climático estão criando crises hídricas que colocam parcela da humanidade em risco de vida, demandando ações rápidas. Cabe destacar aqui que a questão da urgência está além das consequências diretas e imediatas sobre segmentos populacionais no presente: há uma ameaça futura no campo das emergências climáticas que exige ações rápidas, lembrando que uma guinada de postura tardia pode acarretar um ponto de não-retorno (Ripple et al., 2019).

Essa ideia-chave da urgência, mais do que justificar a necessidade da estratégia, orienta e participa da formatação e direcionamento da estratégia. A ideia de urgência aparece logo no início da estratégia, como subtítulo, justificado como que a crise hídrica global urgentemente necessita de mais atenção e ação coordenada, demandando gestão integrada de recursos hídricos mais do que nunca. Ainda, o primeiro parágrafo da Estratégia traz que água é um direito humano fundamental e essencial para o desenvolvimento sustentável, mas que se encontra em ameaça.

A outra ideia-chave presente na estratégia 2020-2025 é a noção de escolhas. Weber-Fahr é muito direta nesse aspecto: "Há escolhas difíceis pela frente, e precisamos que todos na mesa os unam. Por isso, estamos comprometidos em trabalhar em vários setores como forma de alavancar estruturas de políticas globais para motivar todas as partes interessadas a melhorar os processos que levam à mudança de sistemas". Alguns poderiam argumentar que a ideia-chave seria participação. No entanto, a participação, neste caso, vem como desdobramento, consequência da necessidade de escolhas difíceis, que sinalizam para o agravamento de conflitos, e a necessidade de gerenciá-los.

É preciso lembrar que as escolhas cabem aos gestores e formuladores de políticas públicas. $\mathrm{Na}$ ausência de uma consertação e diálogo, escolhas que favoreçam unilateralmente um segmento ou 
grupo de atores sociais, ou mesmo a demora nas escolhas, acirram conflitos. A guerra da água como ficou conhecido o conflito decorrente da privatização das águas em Cochabamba na Bolívia em 2000 (Nickson \& Vargas, 2002; Castro, 2005; Fabricant \& Hicks, 2013) ou o conflito instaurado em Correntina, Bahia, em 2017 e portanto muito recente (Viegas, 2017; Mathias, 2017), mostram a sensibilidade do tema água. Políticas de privatização, políticas de regulação, concessão de outorgas, fiscalização contra retiradas clandestinas, representam todos escolhas. Assim como escolhas ocorreram que determinaram acidentes com barragens (Lacaz et al., 2017; Espindola et al., 2019).

À medida que a crise hídrica, e mesmo a crise social, econômica ou política se acentua, as escolhas se tornam ainda mais determinantes e cruciais. Acirram-se os conflitos na esfera pública, e as lutas no interior do Estado para reafirmar a Água como Direito Humano (Saito, 2018).

Ao colocarmos escolhas como uma ideia-chave, isso também traz responsabilidades para a própria rede GWP, que no passado foi criticada juntamente com o Conselho Mundial da Água na condição de co-organizadores do III Fórum Mundial da Água, em Kyoto, Japão, como portadora ou patrocinadora de uma visão mercantil do acesso à água, sua estreita proximidade com as companhias de água e a distância em relação a um processo participativo pleno (Bakker, 2007).

No entanto, assim como o Fórum Mundial das Águas evoluiu no quesito participação social em 2018, tendo sido considerado o Fórum mais aberto e mais participativo em sua história, também a Global Water Partnership vem internalizando o discurso do direito humano à água e a importância da participação social, reconhecendo a necessidade de inclusão social e o respeito à diversidade cultural ligada aos usos e acessos à água. Já em seu Manual para professores sobre o uso do Toolbox (Thalmeinerova et al., 2017) a GWP propõe a problematização dos conflitos socioambientais em torno da defesa do direito humano à água e da luta pelo acesso à agua, e sua relação com a privatização dos serviços de água. Para isso, entre as atividades apresentadas como sugestão didática, toma-se como exemplo a "Guerra das Águas" de Cochabamba, que inclusive já fazia parte do conjunto de estudos de caso disponíveis no IWRM Toolbox (Zenteno, 2019), sem maior destaque até então. Além desse episódio marcante na história da gestão de recursos hídricos global, o mesmo manual também aponta para a importância de se reconhecer e apreciar as práticas culturais e sagradas ligadas à água, sugerindo atividades vinculadas ao Native Counselling Services of Alberta e os povos indígenas do Canadá.

Outro fator que reforça essa mudança é o fato da última assembléia GWP na América do Sul, realizada em setembro de 2019 em Bogotá, Colômbia, ter aprovado os 4 temas prioritários para os próximos anos na região como sendo a questão da emergência climática, os ODS, a gestão de águas transfronteiriças e a gestão de conhecimento com base no Toolbox, mas com o enfoque na equidade, no reconhecimento da desigualdade social e sua superação, e a diversidade.

\section{OS TEMAS PRIORITÁRIOS NA ESTRATEGIA GWP 2020-2025}

Quando se analisa os temas prioritários na nova estratégia global, é importante comparar o conjunto dos temas escolhidos com aqueles priorizados na Estratégia anterior 2014-2019 (Figura 2).

Na Estratégia 2014-2019 (Global Water Partnership, 2014) haviam 6 temas prioritários e 2 temas transversais, passando agora a existir 3 temas prioritários e 3 temas chamados âncoras que representam os temas transversais (Tabela 1 ).

Como se pode observar, os temas de resiliência climática e águas transfronteiriças se perpetua de uma estratégia para outra, mas outros 4 temas presentes anteriormente deixam de ser priorizados na nova estratégia: ecossistemas, segurança alimentar, energia e urbanização. E entra o tema os Objetivos de Desenvolvimento Sustentável (ODS) que não existia como ação global na época da formulação da Estratégia 2014-2019 por ser posterior a esta.

Cabe nos perguntarmos a causa dessa mudança de priorização dos temas: será que é porque os temas de resiliência climática e águas transfronteiriças são mais urgentes que os demais temas? Será que os outros temas deixaram de ser priorizados globalmente ou foram absorvidos no âmbito dos ODS? Esta última pergunta é interessante porque à primeira vista, a resposta para ela seria sim. No entanto, essa resposta positiva para a pergunta desencadeia uma outra: se os temas anteriores podem estar contidos dentro dos ODS, os temas resiliência climática e águas transfronteiriças também não estariam contidos nos ODS? E sendo a resposta para esta nova pergunta igualmente positiva, resta-nos perguntar por que então esses dois temas foram destacados? 


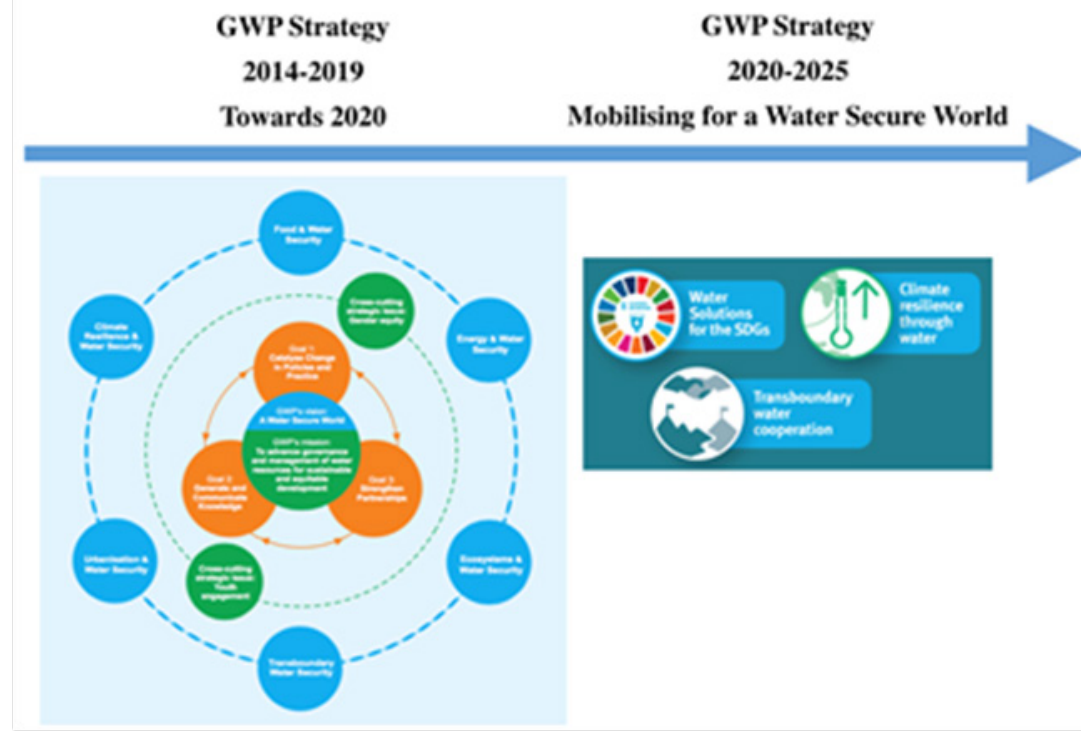

Figura 2. Da Estratégia GWP 2014-2019 à Estratégia GWP 2020-2025. Fonte: Global Water Partnership (2014, 2019).

Tabela 1. Quadro comparativo de temas prioritários e transversais entre a Estratégia GWP 2014-2019 e 20202025.

\begin{tabular}{c|c|c}
\hline \multicolumn{2}{c}{ Estratégia 2014-2019 } & \multicolumn{1}{c}{ Estratégia 2020-2025 } \\
\hline \multirow{4}{*}{ temas prioritários } & ecossistemas e segurança hídrica & \\
\cline { 2 - 3 } & energia e segurança hídrica & \\
\cline { 2 - 3 } & segurança hídrica e alimentar & \\
\cline { 2 - 3 } & resiliência climática e segurança hídrica & resiliência climática \\
\cline { 2 - 3 } & urbanização e segurança hídrica & \\
\cline { 2 - 3 } temas & segurança hídrica transfronteiriça & cooperação em águas transfrontieriças \\
\hline \multirow{3}{*}{ transversais } & & engajamentonto do setor privado \\
\cline { 2 - 3 } & equidade de gênero & contribuição para equidade de gêneros \\
\cline { 2 - 3 } & engajamento de jovens & mobilização de jovens \\
\hline
\end{tabular}

O documento da nova Estratégia 2020-2025 nos dá indicações sobre os motivos por trás dessa decisão: "a oportunidade para aproveitar os marcos de políticas globais e tomar impulso para modificar os sistemas complexos", considerando que "podemos mobilizar com mais ímpeto quando essas forças [os atores sociais] já estão no jogo".

Portanto, a escolha dos temas tem relação com ações globais em andamento, e essa escolha está fortemente baseada na noção de urgência. Há na escolha, portanto, uma certa dose de pragmatismo e oportunismo, buscando alavancar resultados mais expressivos a partir de uma base de apoio: atores envolvidos, ações globais de desenvolvimento (marcos de políticas globais e regionais que tragam foco para as lideranças com medição de progresso) e recursos financeiros engajados.

Comparando com a Estratégia 2014-2019, que continha uma preocupação mais sistêmica em termos de articulação dos temas entre si, cobrindo diferentes aspectos e setores envolvidos no conceito de segurança hídrica, a nova Estratégia 2020-2025 perde essa articulação interna e organicidade, apresentando-se como uma estratégia orientada por resultados, diferentemente da anterior que aparentava ser mais orientada pro processos.

O pragmatismo na nova Estratégia 2020-2025 pode ser também justificado em cima da escolha dos temas transversais que passaram a ser designados como âncoras: os dois temas transversais da estratégia anterior (gênero e juventude) foram mantidos, mas a estes foi acrescentado como âncora o engajamento do setor privado. Considerando a urgência e a preocupação com a prevenção ou solução de conflitos, setores desfavorecidos da sociedade ou comunidades indígenas poderiam ter sido incorporados como alvos prioritários para incorporação em processos voltados para a busca da 
segurança hídrica e a gestão integrada de recursos hídricos. No entanto, tendo a escolha recaído sobre o setor privado, vê-se que a preocupação com o financiamento das ações em prol dos recursos hídricos e gestão integrada dos mesmos, bem como a própria sustentação financeira da rede GWP esteve em primeiro plano. Os contextos de urgência e de crise econômica global que foram discutidos anteriormente justificam-se plenamente.

\section{A AMBIÇÃO COM A ESTRATÉGIA GWP 2020-2025}

Na Estratégia 2020-2025 é dito que se busca implementar uma mudanças no sistema, que se encontra baseada na teoria da mudança (theory of change), conforme Organizational Research Services (2004). Estas mudanças seriam alcançadas a partir de a) passos que promovam a integração da água em alguns países no processo de tomada de decisão, b) mudanças pequenas como resultado de se ter a água à frente de muitas agendas para o desenvolvimento e c) mudanças no sistema tendo os recursos hídricos como parte fundamental da agenda de desenvolvimento em todo o mundo (Figura 3). Porém, esse objetivo projetado a longo prazo se apoia em passos focados em 3 temas prioritários, em que a articulação sistêmica anteriormente mais explícita pode se perder, não se sustentando apenas nas interações internas entre os 17 ODS.

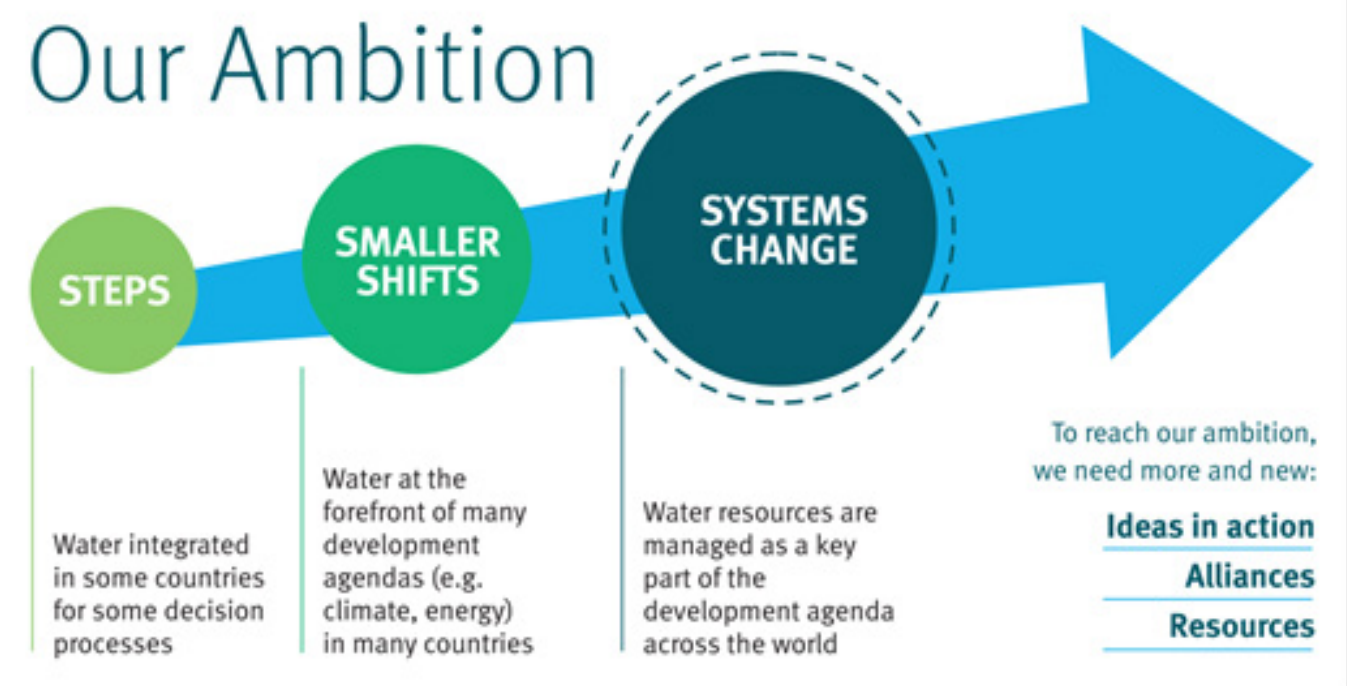

Figura 3. 0 processo de mudança ambicionado pela GWP na Estratégia 2020-2025.

Fonte: GWP (2019, p. 3).

Na Estratégia 2020-2025, dentro do marco referencial da teoria da mudança, acredita-se que as soluções são temporárias mas contém as sementes de um problema futuro porque é útil por um determinado tempo mas logo tem-se que se fazer face a novos desafios que demandam respostas. Esse contínuo processo de ajustes e correções faz parte de um ciclo espiral que interliga água e economia de acordo com John Briscoe, citado por Tushaar Shah (2016, p. 42-43): “[...] uma melhor gestão da água estimula o crescimento, e o crescimento econômico cria mais oportunidades para gerar novas formas de intervenção na gestão dos recursos hídricos".

Para caminhar nessa trajetória, a Estratégia 2020-2025 propõe desenvolver 3 atitudes: mobilizar, atuar, aprender (Figura 4). Dentro de cada um dos temas prioritários, espera-se desenvolver as fortalezas da GWP, de forma a se desenhar estrategicamente as atividades de forma a otimizar o impacto das ações, buscando envolver novos atores ao mesmo tempo que garantimos a participação dos parceiros atuais. Aqui aparece o componente da mobilização, a partir do qual propõe-se criar e manter o impulso da ação e os investimentos (componente da ação), gerando processos para se obter melhoras e inovações ágeis (que responde pelo componente da aprendizagem). 


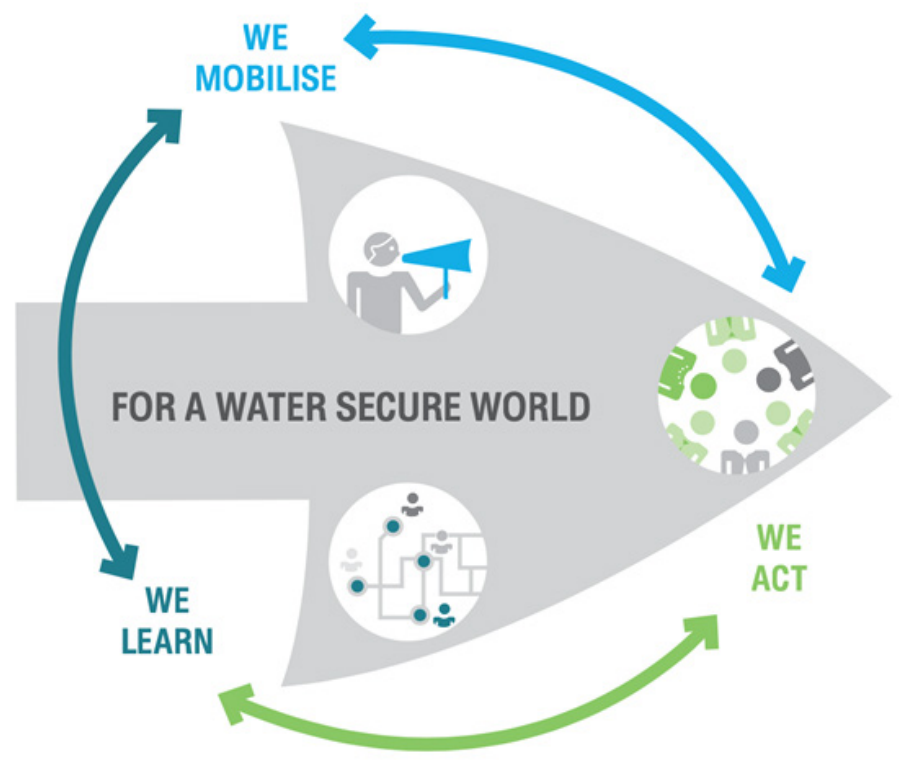

Figura 4. As iniciativas para se promoverem as mudanças ambicionadas pela GWP na Estratégia 2020-2025. Fonte: GWP (2019, p. 16).

No que se refere à mobilização, o documento apresenta o desejo de ampliação da rede por meio do compromisso da escuta às distintas "vozes da água", ou seja, a crescente diversidade de atores sociais envolvidos no uso e gestão da água. Além de ouvir, GWP se compromete nessa Estratégia 2020-2025 a trabalhar em conjunto com os parceiros principais para que estes contribuam na coordenação e colaboração em ações, e apoiará plataformas multi-atores para que estas sejam bem geridas e orientadas para resultados. Espera-se com isso ampliar a rede para além do segmento tradicional de atores ligados diretamente à água, e espera-se também ir além de visões fragmentadas e isoladas setorialmente.

No que se refere à ação, a rede GWP concentrará esforços para promover ações coordenadas e concretas para enfrentar os riscos associados à água e colocar em prática a gestão integrada de recursos hídricos. Para isso, buscar-se-á mudar comportamentos, fortalecer instituições, criar estudos-pilotos, e catalizar investimentos para o desenvolvimento inteligente e sustentável da água.

Finalmente, no que se refere ao aprendizado, a Estratégia 2020-2025 aponta para o compromisso de converter o aprendizado em melhoras permanentes na gestão da água, por meio da promoção de ciclos de retroalimentação apoiados na arquitetura de aprendizagem e conhecimento da GWP. Uma das principais lições já aprendidas é a de que não existe uma solução única universal quando se trata de por a gestão integrada de recursos hídricos em prática, e portanto, é preciso extrair de cada experiência bem-sucedida lições em respeito à diversidade. A rede GWP apresenta uma proposta de engajamento em alianças de aprendizagem e conhecimento, para melhor compreender as gestões bem-sucedidas de recursos hídricos. Apesar da GWP sempre ter tido uma relação de colaboração tanto com a academia como com fóruns de debate, ela acredita ser necessário neste momento de urgência a elevar a colaboração a um outro nível: o que chama de construção de alianças estratégicas de aprendizagem e conhecimento para potencializar as sinergias se manter o foco na ação. Junto a isso, o documento considera que é importante que as oportunidades de aprendizagem estejam disponíveis amplamente, e sejam mais atrativas, sociais e oportunas. É nesse sentido que vislumbra-se a possibilidade de retomar e fortalecer o IWRM Toolbox que já deu um salto em 2017 com o lançamento do Manual de Ensino voltado para docentes universitários (Thalmeinerova et al., 2017). Além disso, como parte da estratégia de fortalecer o conhecimento em torno da gestão integrada de recursos hídricos, propõe-se avaliar as tecnologias em uso de forma que os gestores e tomadores de decisão possam fazer escolhas e incorporar essas tecnologias e soluções inovadoras mais bem-embasados.

Apesar de não estar explícito na Estratégia 2020-2025, este componente da Estratégia GWP 2020-2025 guarda grande sintonia com a nova Década Internacional para Ação "Água para o Desenvolvimento Sustentável” (2018-2028), instituída pela Organização das Nações Unidas por meio da Resolução A/RES/71/222, e que nos encontramos em plena vigência da mesma. Segundo a resolução que instituiu a nova Década Internacional da Água, esta deve ter foco no desenvolvimento sustentável e gestão integrada de recursos hídricos para o alcance dos objetivos sociais, econômicos e 
ambientais, e que para buscar estes objetivos, é fundamental que se desenvolva a geração de conhecimentos e sua disseminação, facilitando o acesso ao conhecimento e intercâmbio de boas práticas.

Espera-se com a combinação desses elementos estratégicos no contexto atual obter os resultados almejados, dentro do quadro referencial da teoria de mudanças (Figura 5).

Uma análise de conteúdo sobre as palavras/expressões utilizadas no documento mostra que além das obviamente esperadas presenças frequentes dos termos água, hídrica, GWP, deve-se apontar como destaque os termos gestão, aprendizagem e apoio, o que corrobora a análise apresentada nesta última seção (Figura 6).

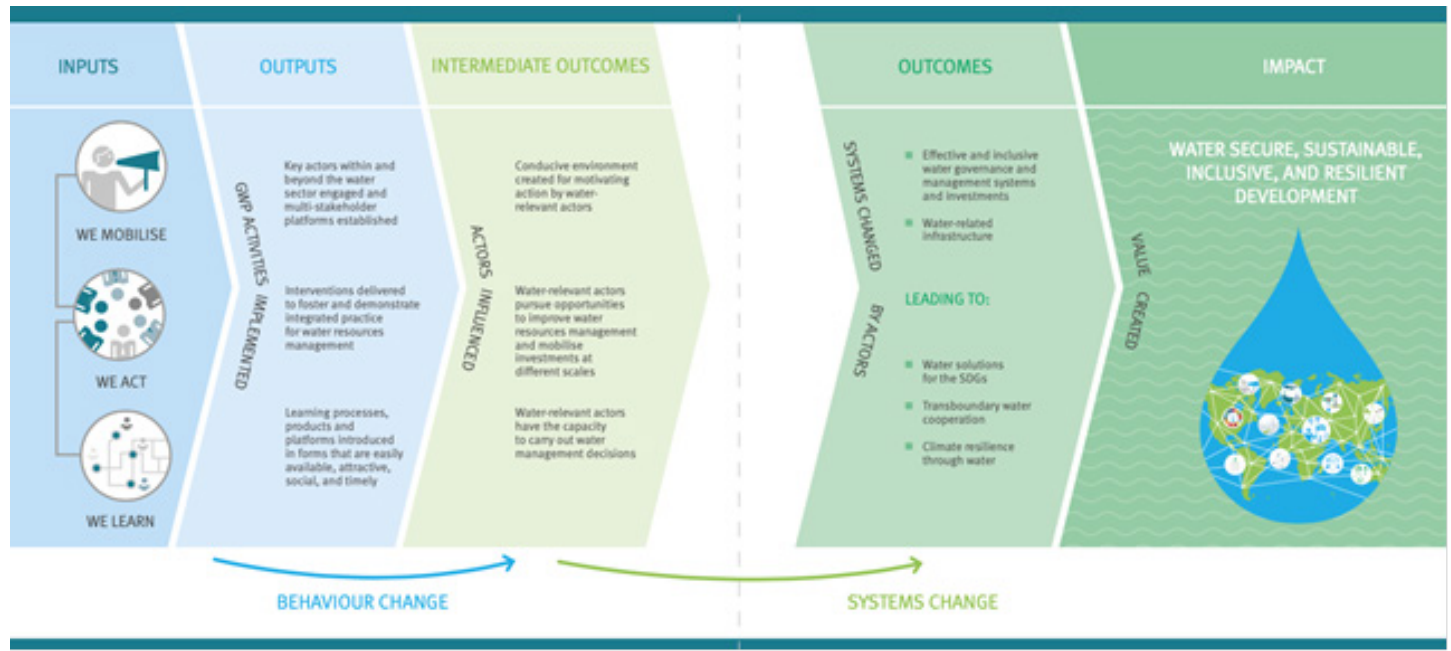

Figura 5. Evolução das mudanças no cenário global de gestão integrada de recursos hídricos buscando maior segurança hídrica, segundo a Estratégia GWP 2020-2025.

Fonte: GWP (2019, p.5-6).

\section{CONSIDERAÇÕES FINAIS}

A Estratégia GWP 2020-2025 foi gestada num contexto em que se percebe a urgência na obtenção de resultados visíveis, o que embora a palavra urgência ou crise não se destaquem no documento em termos de frequência, com base na nuvem de palavras, uma visão analítica permite apreender sua influência.

E justamente é essa influência da urgência na obtenção de resultados visíveis que norteia as escolhas, tanto no que se refere aos temas prioritários (ODS, resiliência climática, águas transfronteiriças), aos temas transversais ou âncoras (gênero, juventude, e engajamento do setor privado), como também de certo modo a busca do apoio na teoria de mudanças e as atividades de mobilização, ação e aprendizado. A urgência dita o viés de pragmatismo e um plano estratégico orientado para resultados. neste documento.

Resta agora trabalharmos para sua implementação, considerando, aqui para a América do Sul, um contexto ligeiramente particular e diferenciado com relação ao conjunto global: um foco maior no respeito à diversidade e no combate às desigualdades sociais, que inclusive foram adotados pela última assembléia GWP na América do Sul, realizada em setembro de 2019 em Bogotá, Colômbia. Aqui na América do Sul, a parte da Estratégia 2020-2025 que se pretende realçar é justamente o ouvir as múltiplas vozes da água. Quem sabe essa vocação social que a seção sul-americana da GWP traz possa contribuir para oxigenar ainda mais os debates globais sobre a gestão integrada de recursos hídricos e a segurança hídrica, dando real expressão ao reconhecimento da água como um direito humano essencial. 


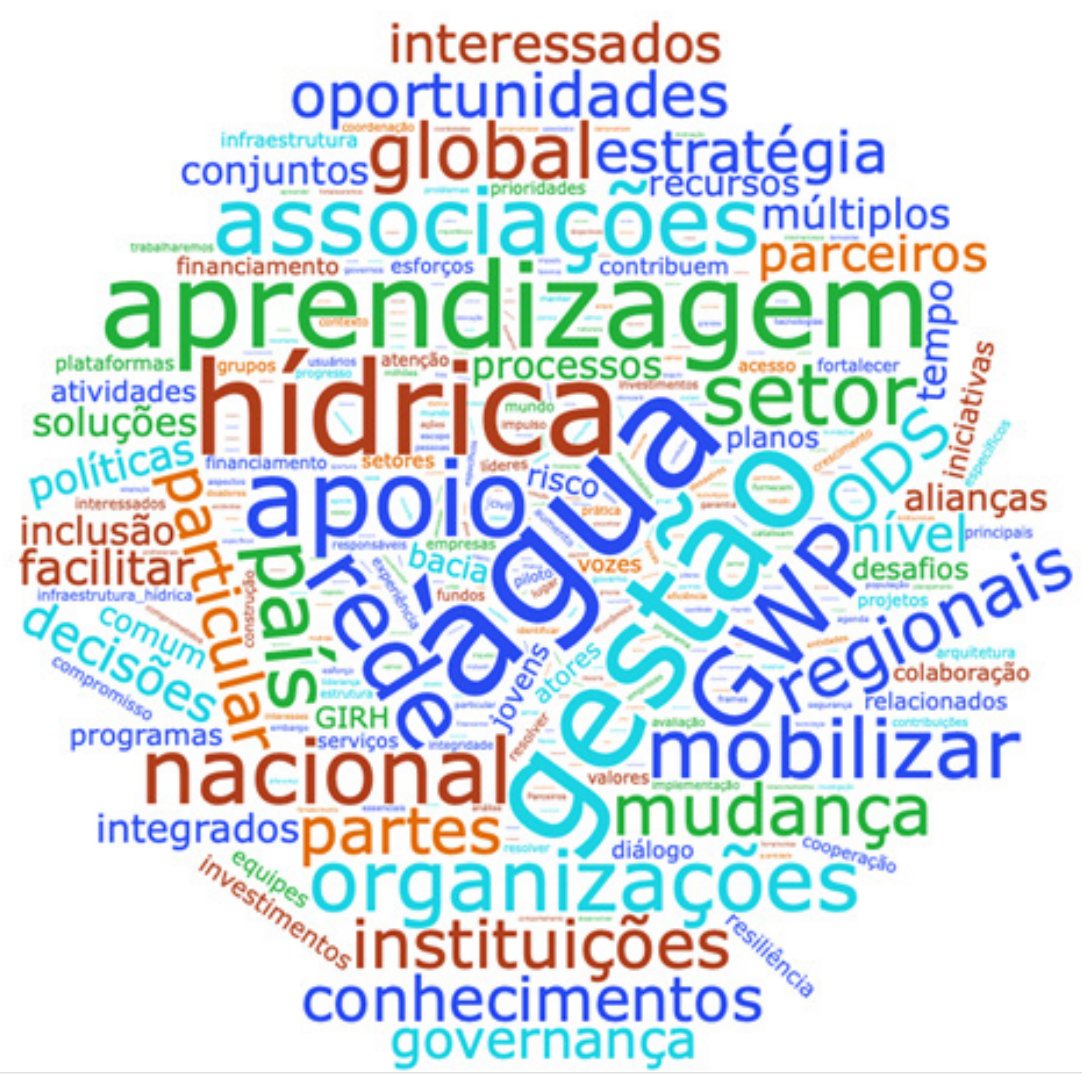

Figura 6. Nuvem de palavras desenvolvida a partir do documento Estratégia GWP 2020-2025. Fonte: Elaboração do autor.

\section{AGRADECIMENTOS}

Agradecimentos são devidos ao Projeto INCT/Odisseia-Observatório das dinâmicas socioambientais: sustentabilidade e adaptação às mudanças climáticas, ambientais e demográficas (chamada INCT - MCTI/CNPq/CAPES/FAPs n.16/2014), Conselho Nacional de Desenvolvimento Científico e Tecnológico (CNPq), Coordenação de Aperfeiçoamento de Pessoal de Nível Superior (CAPES), Fundação de Apoio à Pesquisa do Distrito Federal (FAP-DF) e Global Water Partnership (GWP)

\section{REFERÊNCIAS}

Agência Nacional de Águas - ANA. (2019). Plano Nacional de Segurança Hídrica. Brasília: ANA.

Bakker, K. (2007). The "Commons" Versus the "Commodity": alter-globalization, anti-privatization and the human right to water in the global South. Antipode, 39(3), 430-455.

Castro, J. E. (2005). Agua y gobernabilidad: entre la ideología neoliberal y la memoria histórica. Cuadernos del CENDES, 22(59), 1-21.

Cook, C., \& Bakker, K. (2012). Water security: debating an emerging paradigm. Global Environmental Change, 22(1), 94-102. http://dx.doi.org/10.1016/j.gloenvcha.2011.10.011.

Elliot, L. (2019). World economy is sleepwalking into a new financial crisis, warns Mervyn King. The Guardian, 20 Oct 2019. Recuperado em 17 de novembro de 2019, de https://www.theguardian.com/business/2019/oct/20/world-sleepwalking-to-another-financial-crisissays-mervyn-king

Espindola, H. S., Nodari, E. S., \& Santos, M. A. (2019). Rio Doce: Risks and Uncertainties of the Mariana Disaster (MG). Revista Brasileira de História, 39(81), 1-22.

Fabricant, N., \& Hicks, K. (2013). Bolivia's Next Water War: Historicizing the struggles over Access to Water Resources in the twenty-first century. Radical History Review, 116, 130-145. http://dx.doi.org/10.1215/01636545-1965757.

Global Water Partnership - GWP. (2000). Integrated Water Resources Management - Technical Advisory Committee Background paper n.4. Stockholm: GWP. 
Global Water Partnership - GWP. (2014). GWP Strategy 2014-2019 - Towards 2020. Stockholm: GWP. Recuperado em 18 de novembro de 2019, de https://www.gwp.org/globalassets/global/aboutgwp/strategic-documents/gwp_strategy_towards_2020.pdf

Global Water Partnership - GWP. (2019). GWP Strategy 2020-2025 - Mobilizing for a water secure world. Stockholm: GWP. Recuperado em 18 de novembro de 2019, de https://www.gwp.org/globalassets/global/about-gwp/strategic-documents/gwp-strategy-2020-2025.pdf

Lacaz, F. A. C., Porto, M. F. S., \& Pinheiro, T. M. M. (2017). Tragédias brasileiras contemporâneas: o caso do rompimento da barragem de rejeitos de Fundão/Samarco. Revista Brasileira de Saúde Ocupacional, 42, e9.

Lautze, J., \& Manthrithilake, H. (2012). Water security: old concepts, new package, what value? Natural Resources Forum, 36, 76-87.

Mathias, M. (2017, 20 de novembro). Pesquisador da Fiocruz Pernambuco fala sobre o protesto em Correntina (BA) contra o uso indiscriminado de água para irrigação. Ecodebate. Recuperado em 14 de julho de 2018, de https://www.ecodebate.com.br/2017/11/20/pesquisador-da-fiocruz-pernambuco-fala-sobre-o-protestoem-correntina-ba-contra-o-uso-indiscriminado-de-agua-para-irrigacao/

Nickson, A., \& Vargas, C. (2002). The limitations of water regulation: the failure of the Cochabamba Concession in Bolivia. Bulletin of Latin American Research, 21(1), 99-120.

Organizational Research Services. (2004). Theory of change: a practical tool for action, results and learning prepared for the Annie Casey Foundation. Recuperado em 17 de novembro de 2019, de http://www.aecf.org/upload/publicationfiles/cc2977k440.pdf

Ripple, W. J., Wolf, C., Newsome, T. M., Barnard, P., \& Moomaw, W. R. (2019). World Scientists' Warning of a Climate Emergency. BioScience, (first view 2019), biz088. http://dx.doi.org/10.1093/biosci/biz088.

Saito, C. H. (2017, setembro). Quais seriam as Questões Globais que desafiam a Educação Ambiental? Para além do modismo, uma análise sistemática e uma visão sistêmica. Revista Eletrônica do Mestrado em Educação Ambiental, 4-24. número especial XVI EPEA.

Saito, C. H. (2018). Segurança hídrica e direito humano à água. In A. Ruscheinsky, C. Calgaro, \& T. Weber. (Orgs.). Ética, direito socioambiental e democracia (pp. 94-108). Caxias do Sul: Educs.

Shah, T. (2016). Increasing water security: the key to implementing the Sustainable Development Goals - TEC background paper n. 22 (52 p.). Stockholm: Global Water Partnership.

Solanes, M., \& Gonzales-Villarreal, F. (1999). The Dublin Principles for Water as Reflected in a Comparative Assessment of Institutional and Legal Arrangements for Integrated Water Resources Management - Technical Advisory Committee Background paper n. 3. Stockholm: GWP.

Thalmeinerova, D., Fábrega, J. R., Guan, Y., Janusz-Pawletta, B., Kileshye-Onema, J. M., \& Saito, C. H. (Eds.), (2017) IWRM Toolbox Teaching Manual. Stockholm: Global Water Partnership. Recuperado em 18 de novembro de 2019, de http://www.gwp.org/globalassets/global/toolbox/references/iwrm_teaching_manual.pdf

Un-Water. (2013). Water security and the global water agenda. Gênova: UN-Water. Recuperado em 18 de novembro de 2019, de http://www.unwater.org/app/uploads/2017/05/analytical_brief_oct2013_web.pdf

Van_Beek, E., \& Arriens, W. L. (2014). Water Security: putting the concept into practice - TEC background paper $\mathrm{n}$. 20 (55 p.). Stockholm: Global Water Partnership.

Viegas, E. C. (2017, 18 de novembro). Guerra pela água na Bahia (e no planeta) não é nenhuma novidade. Revista Conjur.

Witter, S. G., \& Whiteford, S. (1999). Water security: the issues and policy challenges. International Review of Comparative Public Policy, 11, 1-25.

Zenteno, R. B. (2019). The 'Water War' to resist privatisation of water in Cochabamba, Bolivia. Stockholm: Global Water Partnership. Recuperado em 18 de novembro de 2019, de http://www.gwp.org/globalassets/documents/downloads-misc/cs-157-bolivia.pdf

\section{Dados do Autor:}

Carlos Hiroo Saito

Universidade de Brasília, Instituto de Ciências Biológicas, Brasília-DF, Brasil

Global Water Partnership, GWP-Brasil 